\title{
Efficacy and Sagittal Parameters of Debridement and Bone Grafting using Internal Fixation in the Treatment of Kyphotic Cervical Tuberculosis: A Case Series
}

\section{Haopeng Luan}

The First Affiliated Hospital of Xinjiang Medical University

Kai Liu

The First Affiliated Hospital of Xinjiang Medical University

Qiang Deng ( 1714250017@qq.com )

The First Affiliated Hospital of Xinjiang Medical University

Weibin Sheng

The First Affiliated Hospital of Xinjiang Medical University

Maierdan Maimaiti

The First Affiliated Hospital of Xinjiang Medical University

Hailong Guo

The First Affiliated Hospital of Xinjiang Medical University

\section{Research Article}

Keywords: Bone grafting, debridement, internal fixation, spine, tuberculosis

Posted Date: October 15th, 2021

DOI: https://doi.org/10.21203/rs.3.rs-965602/v1

License: @ (1) This work is licensed under a Creative Commons Attribution 4.0 International License. Read Full License 


\section{Abstract}

Background: To evaluate the efficacy of debridement and bone grafting using internal fixation in the treatment of kyphotic cervical tuberculosis, and analyze the changes of pre-operation and post-operation sagittal parameters, which related to the surgical indications.

Methods: Clinical and radiographic data of patients with kyphotic cervical TB treated by debridement and BGIF at our hospital from January 2010 to December 2017 were analyzed retrospectively. The sagittal parameters of the cervical vertebra at the preoperation, post-operation, and last follow-up were documented and were compared.

Results: Eighteen patients of simple anterior approach debridement and fusion with internal fixation (group A), and 5 patients underwent anterior debridement and fusion, combined with posterior internal fixation (group AP). In the comparison of preoperative sagittal parameters, significant improvement after surgery was observed in both groups, included Cobb angle, SCA, C2-C7SVA, and CG-SVA $(P<0.05)$. There were no significant differences in T1 Slope, NT, and TIA $(P>0.05)$.

Conclusions: In the treatment of kyphotic cervical TB, the characteristics of the lesion, the degree of kyphosis and spinal cord nerve compression damage can be presented clearly by the radiographic sagittal parameters, which does a favor to individualize the choice of surgical approach safely and effectively.

\section{Background}

Spinal tuberculosis (TB) is the most common type of osteoarticular TB, accounting for $50 \%$ of all skeletal TB $[1,2]$. The incidence of cervical TB is rare, approximately $4.2-12 \%$ of spinal TB [3-5]. However, the anatomical structure of the cervical vertebra is complex, which is adjacent to important structures (such as medulla oblongata, cervical spinal cord, and cerebellum), and easily form the compression symptom of posterior pharyngeal wall abscess. The abscess may spread to the surrounding tissues and compresses the trachea, esophagus, and neck vessels, which caused neurological symptoms due to posterior compression of the spinal cord by a cold abscess in some patients [6-10]. Mostly, the intervertebral disc is involved, then resulting in cervical instability and spinal cord neurological dysfunction.

At present, comprehensive treatment, based on anti-TB (TB) chemotherapy, surgery, and nutritional support therapy, is usually used for cervical spine TB [11-16]. Anti-TB chemotherapy is effective and practical in the early stage of TB. However, the early symptoms of TB disease are too insidious to notice and are diagnosed until the middle or advanced stage $[11,12,16]$. Hence, surgical intervention is required by patients with cervical deformity, neurological compression symptoms, and necrotic tissue, which is caused by an abscess or drug resistance of anti-TB [17]. How to treat middle- and late-stage TB patients with cervical kyphosis has become a huge challenge gradually for orthopedic surgeons.

It has been reported that the anterior approach or combined anterior and posterior approach debridement surgery is a practical treatment for kyphotic cervical TB $[18,19]$. Vertebral body reconstruction after debridement has become a difficult problem of the unique anatomy of the cervical spine. The choice of surgical approach is still controversial, which determines the options of surgery to reconstruct the vertebral body. Via published articles [6-8, 18-21], few studies analyzed vertebral radiographic sagittal parameters before and after surgery and combined the changes of cervical sagittal reconstruction with the assessment of the patient's postoperative function recovery. For these, the purpose of this study was to evaluate the relationship between cervical vertebral radiographic sagittal parameters and the patient's postoperative function recovery, assess the clinical efficacy of the anterior approach, and combined anterior and posterior approach vertebral debridement and bone grafting using internal fixation (BGIF), and summarize the surgical indications.

\section{Methods}

\section{Study design}

From January 2010 to December 2017, the medical records and radiographs were evaluated retrospectively of all patients, whose kyphotic cervical TB were treated by debridement and BGIF, after written informed consent from participates and approval from the 
Ethics Committee of our hospital were received. Inclusion criteria are as follows: the entire spine radiological indications (X-ray radiography, $\mathrm{CT}$, and $\mathrm{MRI}$ ), and hematological and pathological examinations; typical clinical presentation (low-grade fever, pain, night sweats, weight loss, kyphosis, and neurological dysfunction); managed by debridement and BGJF. Patients were excluded because of incomplete medical records, poor compliance, other treatments were performed, or follow-up time less than two years.

The patients were divided into two groups according to the surgical approaches, simple anterior approach of debridement and BGIF (group A), anterior debridement and bone grafting combined with the posterior approach of internal fixation (group AP). The previous surgical and medical treatment, associated injury or diseases, the record of antimicrobial utilization, biopsy, or culture results of secretions were recorded. The C-reactive protein (CRP) level, white blood cell (WBC) count, procalcitonin, erythrocyte sedimentation rate (ESR), and T-SPOT were examined and documented.

\section{Preoperative management}

The surgery plan was drafted based on the anteroposterior and lateral radiographs, CT, and MRI films of the entire spine. Patients were treated with the standardized anti-TB chemotherapy (isoniazid $300 \mathrm{mg}$, rifampicin $450 \mathrm{mg}$, ethambutol $1200 \mathrm{mg}$, and pyrazinamide $1500 \mathrm{mg}$ ) for at least 2 weeks before surgery. Comorbidity (hypertension, diabetes, malnutrition, etc.) was controlled effectively with goals of blood pressure less than $140 / 90 \mathrm{mmHg}$, blood glucose less than $11.0 \mathrm{mmol} / \mathrm{L}$, and improved appetite. When ESR and the physical temperature returned to normal, and anemia and hypoproteinemia were corrected completely, the surgical procedure was ready to be performed. When the symptoms of spinal cord compression were worsened progressively during anti-TB treatment, and emergency surgery was required.

\section{Surgical technique}

\section{Group A}

The patient was placed in the supine position. After the general anesthesia took effect, the cervical spine was hyperextended slightly by padding a cotton pad under both shoulders, and the surgical area was disinfected and draped routinely. After X-ray fluoroscopic positioning, an anterior right transverse incision length of about $4 \mathrm{~cm}$ was made on the right side of the anterior neck. The skin, subcutaneous tissue, and platysma muscle were incised layer by layer to enter from the inner edge of the sternocleidomastoid muscle, and the surrounding tissues were separated bluntly using a periosteal elevator. More attention should be paid to protect the trachea, carotid artery, and throat wall, and the trachea and esophagus were retracted inward carefully. Then the carotid sheath was retracted outwards, and the anterior fascia of the exposed vertebra was incised layer by layer to expose the anterior aspect of the vertebral body. The anterior cervical abscess, destroyed the vertebral body, and the intervertebral disc was removed, and bone destruction in the vertebral body was observed. The worm-like necrotic tissue was removed by a curette, and the posterior longitudinal ligament was exposed by a distractor. After confirming that there was no compression of the spinal cord, the edge of the vertebral body was trimmed to expose the subchondral bone. The autologous iliac bone or allogeneic bone of the corresponding size was taken to embed the defect and fixed by an anterior cervical titanium plate. After the X-ray fluoroscopic of the internal fixation position was satisfactory, a large amount of $0.9 \%$ saline was applied for irrigation. The drainage was placed, and the incision was sutured layer by layer.

\section{Group AP}

The preoperative preparation was similar to the above. The patient was placed firstly in the supine position, and after general anesthesia took effect, cranial traction was performed. The skin of the surgical area was disinfected and draped, and a transverse anterior cervical incision was performed. The skin, subcutaneous tissue, and platysma Colli muscle were incised layer by layer, and the inner edge of the sternocleidomastoid muscle was entered. The surrounding tissues were separated bluntly and entered along the tracheoesophageal sheath and carotid sheath to expose the anterior edge of the cervical vertebral body. The anterior cervical abscess, dead bone, surrounding necrotic tissue, and intraspinal abscess were removed carefully after complete exposure (necrotic tissue was sent for pathological examination). The spinal cord compression was decompressed absolutely. The titanium cage of the corresponding length (implanted with autologous iliac bone or allogeneic bone particles in the cage) was placed in the defect caused by debridement, and the titanium cage was fixed with screws. The drainage was placed, and the incision was sutured layer by layer. Then the patient's position was changed to the prone position, the surgical area was disinfected and draped again. A posterior midline neck incision was performed, and the skin and subcutaneous tissue were incised layer by layer. The paraspinal 
muscles were exposed to the lateral border of the facet. The posterior approach of internal fixation was performed using cervical lateral mass or pedicle screws, then connected the rods and screw caps were installed for fixation. A large amount of normal saline was used to irrigate the incision and the streptomycin $(2 \mathrm{~g})$ was placed on both surgical areas. The drainage was placed, and the incision was sutured layer by layer.

\section{Postoperative management}

After the surgical procedure, the patient's physical signs were monitored, included blood pressure, respiration, and pulse. The drainage tube was removed when the fluid volume was $<50 \mathrm{~mL}$ within 24 hours. The X-ray was re-examined on the fifth postoperative day to determine whether the internal fixation position and bone grafting area were stable. After the internal fixation position was satisfactory, patients were encouraged to wear a neck rest and walking with the help of walking aid to prevent joint stiffness. If the position of the internal fixation was not correct or loosing, the above surgery was managed. Patients were assessed for bone healing and the stability of internal devices by the X-ray, CT, and MRI at 1, 3, 6, and 12 months postoperatively. The anti-TB chemotherapy was continued for at least ten months. Simultaneously, ESR, CRP levels, and liver and kidney function were monitored every 6 weeks.

\section{Data Collection and Outcome Evaluation}

The clinical demographic data, operative time, amount of intra-operative bleeding, and follow-up time for each patient were recorded. ESR and CRP tests were used to monitor TB activity. The ASIA spinal cord injury grade, JOA cervical function score, NDI, and VAS for pain were used to assess the patients' functional improvement and the quality of life. Anteroposterior and lateral Xrays of the whole spine in the standing position were performed to assess the correction of the deformity by measuring vector parameters, as following: C0-2 Cobb angle, C2-7 Cobb angle, local Cobb angle, SCA, C2-7SVA, CG-7SVA, T1S, NT, and TIA. Eck fusion grading system was used to assess the bone graft fusion, and the complications were recorded, including sinus formation, bone graft collapsed, and vertebral bone destruction.

\section{Statistical analysis}

Data were input in a Microsoft Excel spreadsheet (Redmond, WA, USA) and reported as frequencies and percentages, then analyzed by the SPSS 20.0 software package (Chicago, IL, USA). Comparisons between two groups were conducted using the chisquare test or t-test. Statistical significance was $\mathrm{p}<0.05$.

\section{Results}

A total of 23 patients were included in the study with an average age of 46.74 years (range, 23-74 years), included 8 males and 15 females. The mean postoperative follow-up time was 25.9 months (12-45 months). Eighteen patients underwent the anterior approach of debridement and BGIF (group A), and 5 patients were managed by the anterior approach of debridement, bone grafting combined with the posterior approach of internal fixation (group AP). Various degrees of the pain in neck and shoulder were observed in all patients. Neurological dysfunction occurred in 12 patients with a duration of 2 to 12 months, such as limited neck and shoulder movement, upper limb muscle weakness, and hypoesthesia. The ESR and CRP elevation occurred in all cases (Table 1). Typical TB symptoms, such as low-grade fever, night sweats, weight loss, and fatigue were presented in 19 patients. At least 2-4 weeks of regular quadruple anti-TB chemotherapy (HREZ) before the operation were managed for all patients. Refer to Figures 1-2 for details on the whole treatment of kyphotic cervical TB, which was described by this study. 
Table 1

Basic data of 23 patients with kyphotic cervical tuberculosis

\begin{tabular}{|c|c|c|c|c|c|c|c|c|}
\hline \multirow[t]{2}{*}{ Case } & \multirow{2}{*}{$\begin{array}{l}\text { Age } \\
\text { (years)/gender } \\
(\mathrm{M}, \mathrm{F})\end{array}$} & \multirow{2}{*}{$\begin{array}{l}\text { Lesion } \\
\text { location }\end{array}$} & \multirow{2}{*}{$\begin{array}{l}\text { Follow-up } \\
\text { time } \\
\text { (months) }\end{array}$} & \multirow{2}{*}{$\begin{array}{l}\text { Approach } \\
\text { of surgery }\end{array}$} & \multicolumn{2}{|c|}{ ESR (mm/h) } & \multicolumn{2}{|c|}{ CRP (mg/L) } \\
\hline & & & & & $\begin{array}{l}\text { Pre- } \\
\text { operation }\end{array}$ & $\begin{array}{l}\text { After } 3 \\
\text { postoperative } \\
\text { months }\end{array}$ & $\begin{array}{l}\text { Pre- } \\
\text { operation }\end{array}$ & $\begin{array}{l}\text { After } 3 \\
\text { postoperative } \\
\text { months }\end{array}$ \\
\hline 1 & $35 / F$ & $\mathrm{C} 6-\mathrm{C} 7$ & 33 & $A$ & 47 & 4 & 18.78 & 7.35 \\
\hline 2 & $26 / F$ & C3-C6 & 25 & $A$ & 32 & 3 & 28.58 & 4.93 \\
\hline 3 & $36 / \mathrm{M}$ & C6-C7 & 32 & $A$ & 53 & 11 & 23.56 & 7.53 \\
\hline 4 & $52 / \mathrm{M}$ & C3-C4 & 45 & $A$ & 44 & 6 & 24.09 & 3.87 \\
\hline 5 & $73 / F$ & C5-C6 & 32 & A & 39 & 18 & 57.33 & 10.55 \\
\hline 6 & $35 / M$ & $\mathrm{C} 6-\mathrm{C} 7$ & 41 & $A$ & 37 & 4 & 20.35 & 9.05 \\
\hline 7 & $65 / F$ & C3-C4 & 22 & A & 38 & 3 & 10.33 & 8.53 \\
\hline 8 & $57 / F$ & $\mathrm{C} 2-\mathrm{C} 3$ & 12 & AP & 28 & 7 & 32.76 & 7.89 \\
\hline 9 & $46 / F$ & C3-C5 & 18 & $A$ & 67 & 4 & 36.51 & 5.40 \\
\hline 10 & $27 / F$ & $\mathrm{C} 3-\mathrm{C} 4$ & 19 & $A$ & 50 & 23 & 11.25 & 9.19 \\
\hline 11 & $33 / F$ & C4-C5 & 21 & $A$ & 33 & 3 & 27.41 & 4.62 \\
\hline 12 & $63 / \mathrm{M}$ & C3-C5 & 13 & AP & 28 & 8 & 75.94 & 14.96 \\
\hline 13 & $55 / F$ & $\mathrm{C} 6-\mathrm{C} 7$ & 16 & $A$ & 39 & 6 & 37.95 & 9.41 \\
\hline 14 & $32 / F$ & C4-C5 & 27 & $A$ & 47 & 16 & 37.36 & 8.37 \\
\hline 15 & $74 / \mathrm{M}$ & C2-C3 & 31 & $A$ & 44 & 9 & 43.35 & 13.28 \\
\hline 16 & $41 / \mathrm{M}$ & C5-C7 & 32 & $\mathrm{AP}$ & 57 & 10 & 28.33 & 4.43 \\
\hline 17 & $62 / M$ & C3-C4 & 21 & A & 38 & 8 & 26.49 & 6.35 \\
\hline 18 & $49 / \mathrm{M}$ & C5-C6 & 26 & A & 34 & 3 & 12.38 & 5.94 \\
\hline 19 & $30 / F$ & C4-C5 & 17 & $A$ & 45 & 9 & 14.96 & 7.30 \\
\hline 20 & $49 / F$ & C5-C6 & 28 & $\mathrm{AP}$ & 44 & 15 & 9.34 & 7.28 \\
\hline 21 & $63 / F$ & C4-C6 & 34 & $A$ & 41 & 3 & 47.98 & 9.88 \\
\hline 22 & $49 / F$ & C5-C6 & 37 & $A$ & 32 & 5 & 38.76 & 7.61 \\
\hline 23 & $23 / F$ & C1-C3 & 15 & AP & 51 & 7 & 34.79 & 9.06 \\
\hline
\end{tabular}

\section{Imaging evaluation parameters}

The sagittal parameters were improved significantly before and after surgery in both groups. Briefly, the preoperative local Cobb angle was corrected from $25.13 \pm 8.28^{\circ}$ and $15.47 \pm 10.16^{\circ}$ to $-9.74 \pm 3.71^{\circ}$ and $-11.05 \pm 5.02^{\circ}$ after surgery in both groups, the preoperative SCA was changed from $91.74 \pm 8.96$ and $98.76 \pm 4.61$ to $80.16 \pm 7.05$ and $82.23 \pm 1.13$ after surgery, and the preoperative C2-C7SVA was corrected from $36.48 \pm 10.35$ and $32.44 \pm 4.24$ preoperatively to $11.65 \pm 4.38$ and $11.52 \pm 4.02$ postoperatively. Significant improvement of postoperative sagittal parameters (C0-C2Cobb angle, C2-C7Cobb angle, local Cobb angle, SCA, C2-C7SVA, and CG-SVA) was obtained in both groups $(P<0.05)$. However, there were no significant differences in T1Slope, NT, and TIA before and after surgery of the two groups $(P>0.05)$, and no significant loss of sagittal correction was 
observed during the postoperative follow-up (Table 2). At 6 postoperative months, 17 patients achieved grade I and 6 patients achieved grade II fusion in the bone grafting area, and 23 patients achieved the grade I fusion in the bone grafting area.

Table 2

Comparison of sagittal parameters in the two groups at pre-operation and post-operation, and the last follow-up

\begin{tabular}{|c|c|c|c|c|c|c|c|c|}
\hline \multirow[t]{2}{*}{ Parameter } & \multicolumn{2}{|l|}{ Pre-operation } & \multicolumn{2}{|c|}{ Post-operation } & \multicolumn{2}{|l|}{ Last follow-up } & \multirow[t]{2}{*}{ P1 } & \multirow[t]{2}{*}{$\mathrm{P} 2$} \\
\hline & Group A & Group AP & Group A & Group AP & Group A & Group AP & & \\
\hline $\begin{array}{l}\text { C0-C2 } \\
\text { Cobb } \\
\text { angle }\left({ }^{\circ}\right)\end{array}$ & $-25.51 \pm 7.17$ & $-27.15 \pm 3.01$ & $-20.80 \pm 5.34$ & $-20.72 \pm 1.03$ & $-20.53 \pm 2.89$ & $-19.86 \pm 1.61$ & 0.015 & 0.017 \\
\hline $\begin{array}{l}\text { C2-C7 } \\
\text { Cobb } \\
\text { angle }\left({ }^{\circ}\right)\end{array}$ & $14.26 \pm 9.93$ & $15.47 \pm 10.16$ & $-15.03 \pm 8.10$ & $-16.49 \pm 8.11$ & $-14.81 \pm 7.37$ & $-15.54 \pm 6.02$ & $<0.001$ & $<0.001$ \\
\hline $\begin{array}{l}\text { Local } \\
\text { Cobb } \\
\text { angle }\left({ }^{\circ}\right)\end{array}$ & $25.13 \pm 8.28$ & $26.18 \pm 9.93$ & $-9.74 \pm 3.71$ & $-11.05 \pm 5.02$ & $-10.04 \pm 3.54$ & $-11.13 \pm 4.81$ & $<0.001$ & 0.002 \\
\hline $\begin{array}{l}\text { Spino } \\
\text { cranial } \\
\text { angle }\left({ }^{\circ}\right)\end{array}$ & $91.74 \pm 8.96$ & $98.76 \pm 4.61$ & $80.16 \pm 7.05$ & $82.23 \pm 1.13$ & $81.65 \pm 6.78$ & $83.93 \pm 2.97$ & $<0.001$ & 0.002 \\
\hline $\begin{array}{l}\text { TI Slope } \\
\left({ }^{\circ}\right)\end{array}$ & $15.04 \pm 7.43$ & $17.01 \pm 7.91$ & $19.16 \pm 8.36$ & $19.34 \pm 6.87$ & $19.42 \pm 8.23$ & $20.44 \pm 7.15$ & 0.008 & 0.083 \\
\hline $\begin{array}{l}\text { Neck tilt } \\
\left(^{\circ}\right)\end{array}$ & $43.54 \pm 9.89$ & $44.20 \pm 3.03$ & $40.38 \pm 11.09$ & $41.69 \pm 14.20$ & $40.59 \pm 10.74$ & $41.72 \pm 12.93$ & 0.241 & 0.656 \\
\hline $\begin{array}{l}\text { Thoracic } \\
\text { inlet angle } \\
\left({ }^{\circ}\right)\end{array}$ & $58.62 \pm 12.59$ & $61.21 \pm 5.68$ & $59.55 \pm 9.46$ & $61.03 \pm 9.80$ & $60.01 \pm 9.15$ & $62.16 \pm 7.02$ & 0.647 & 0.846 \\
\hline $\begin{array}{l}\text { C2-C7 } \\
\text { SVA (mm) }\end{array}$ & $36.48 \pm 10.35$ & $32.44 \pm 4.24$ & $11.65 \pm 4.38$ & $11.52 \pm 4.02$ & $8.44 \pm 3.01$ & $8.46 \pm 0.29$ & $<0.001$ & $<0.001$ \\
\hline $\begin{array}{l}\text { CG-7 SVA } \\
(\mathrm{mm})\end{array}$ & $45.34 \pm 13.46$ & $44.99 \pm 7.57$ & $27.20 \pm 12.63$ & $26.38 \pm 14.42$ & $24.70 \pm 12.17$ & $20.62 \pm 10.08$ & $<0.001$ & 0.017 \\
\hline
\end{tabular}

\section{Laboratory test results and postoperative function recovery}

ESR and CRP levels were decreased significantly in both groups after surgery in all patients (Table 1). In group A, preoperative and last follow-up JOA scores were $6.31 \pm 2.03$ and $15.87 \pm 0.87$ respectively; VAS scores were $7.30 \pm 1.52$ and $1.74 \pm 0.61$; NDI was $32.61 \pm 5.47$ and $8.83 \pm 2.31$. Preoperative and last follow-up JOA scores were $7.00 \pm 2.35$ and $15.20 \pm 1.09$, VAS scores were 7.40 \pm 1.34 and $1.80 \pm 0.45$, and NDI were $36.20 \pm 3.27$ and $9.60 \pm 1.82$ in group AP. There were significant differences in the JOA score, VAS, and NDI between pre-operation and last follow-up $(P<0.05)$. According to the ASIA classification, 5 cases improved from preoperative grade $C$ to grade $E, 16$ cases improved from preoperative grade $D$ to grade $E$ (total rate of grade $E$ 91.3\%). Two patients were evaluated as grade $\mathrm{C}$ since the severe damage to the vertebral body and worsen compression of the spinal cord (Table 3). 
Table 3

Comparison of JOA score, VAS score, and NDI index of the two groups

\begin{tabular}{|c|c|c|c|c|c|c|c|c|}
\hline & \multicolumn{2}{|c|}{ Pre-operation } & \multicolumn{2}{|c|}{ Post-operation } & \multicolumn{2}{|c|}{ Last follow-up } & \multirow[t]{2}{*}{ P1 } & \multirow[t]{2}{*}{ P2 } \\
\hline & Group A & Group AP & Group A & Group AP & Group A & Group AP & & \\
\hline $\begin{array}{l}\text { JOA cervical } \\
\text { function score }\end{array}$ & $6.31 \pm 2.03$ & $7.00 \pm 2.35$ & $14.96 \pm 1.58$ & $14.00 \pm 1.87$ & $15.87 \pm 0.87$ & $15.20 \pm 1.09$ & $<0.001$ & $<0.001$ \\
\hline $\begin{array}{l}\text { Cervical VAS } \\
\text { score }\end{array}$ & $7.30 \pm 1.52$ & $7.40 \pm 1.34$ & $3.01 \pm 0.90$ & $3.00 \pm 1.22$ & $1.74 \pm 0.61$ & $1.80 \pm 0.45$ & $<0.001$ & 0.002 \\
\hline NDI & $32.61 \pm 5.47$ & $36.20 \pm 3.27$ & $13.69 \pm 2.88$ & $13.60 \pm 3.51$ & $8.83 \pm 2.31$ & $9.60 \pm 1.82$ & $<0.001$ & $<0.001$ \\
\hline
\end{tabular}

P1: Comparison of parameters at preoperative and last follow-up of group A; P2: Comparison of parameters at preoperative and last follow-up of AP group.

\section{Complications}

There were 2 cases of complications, unfortunately. The muscle strength of both upper limbs decreased from grade 5 to grade 3 in 1 patient with normal sensory function after surgery. By the neurotrophic drugs, nerve electrical stimulation therapy, and physical rehabilitation, the muscle strength returned to normal at 2 weeks later. Furthermore, incision sinus formation was observed in one case at 3 months after surgery, which healed after the debridement operation. There was no fracture or displacement of the internal fixation during the follow-up. The stability of the cervical spine was reconstructed, and there was no recurrence of TB.

\section{Discussion}

The common site of extra-pulmonary TB and the most severe form of osteoarticular TB is spinal TB, which is a widespread infectious disease problem in animal husbandry areas and developing areas $[8,20]$. Because of its unique anatomical structure, the early symptoms of cervical TB are too tricky to notice. The neck and shoulder pain and discomfort of neck and shoulder occur first mostly. When the disease continues to develop, the posterior pharyngeal wall abscess is created slowly. The surrounding tissues, like the trachea and esophagus, may be compressed by this spreading cold abscess. The nerve root compression symptoms were caused mostly by the cold abscess posterior compressing. The anterior and middle columns of the spine are affected mainly by cervical TB, resulting in cervical kyphosis, neck stiffness, and neurological dysfunction caused by spinal cord compression. The single-level infections of the vertebral body are rare [6-8]. In this study, the lesions of patients with kyphotic cervical TB were concentrated mostly in the lower level of the cervical spine (C3 - C6). Involving more than two vertebral bodies occurred in all patients, who forming local kyphotic deformity. Typical cervical spinal cord compression symptoms were observed in 12 cases. The purpose of surgery is to decompress the compression symptoms of the spinal cord effectively, reconstruct the stability of the vertebral body, and restore the normal sequence in the sagittal position of the spine vertebral body.

The treatment published by a previous study of the early stage cervical vertebral TB was regular anti-TB chemotherapy and symptomatic treatment $[8,11,16,20]$. But the long-term medication cycle and the increasing drug resistance, there is a great incidence of chance for the lesion to continue to the advanced stage, which may lead to progressive aggravation of spine deformity or vertebral body instability [22, 23]. For severe bone destruction and poor cervical stability after conservative treatment, surgical intervention is usually required. At present, the simple anterior approach of debridement and spine reconstruction surgery is a commonly used surgical method for the treatment of cervical TB, since the characteristics of simple approach, simplified procedure, removal of the lesion completely, and reliable structural reconstruction $[1,6-8,24,25]$. The case series of 17 patients with cervical TB who were managed for the anterior approach of debridement and BGIF, were reported by Wu et al. [26] The bone grafting fusion of the vertebral body and improved neurological dysfunction were achieved. In this study, 18 patients of group $\mathrm{A}$ were treated by the anterior approach of debridement and BGIF, the sagittal sequence of the cervical vertebral body was corrected significantly. Briefly, the preoperative local Cobb angle was improved from $25.13 \pm 8.28^{\circ}$ to $-9.74 \pm 3.71^{\circ}$ after surgery, the SCA was improved from $91.74 \pm 8.96$ to $80.16 \pm 7.05$ postoperatively, the C2-C7SVA was improved from $36.48 \pm 10.35$ to $11.65 \pm 4.38$ postoperatively. The patient's neurological recovery was satisfactory, and the neck and shoulder pain was relieved completely. It 
was recommended by us that the anterior approach of debridement and BGIF should be selected in the following cases: (1) the TB lesion eroded or destroyed the vertebral body slightly, and obvious cold abscess appears in front; (2) there was no obvious vertebral collapse, intervertebral space lesion, only slight infiltration of the adjacent vertebral body with no pedicle destruction; (3) patients with the poor physical condition. In these cases, the anterior approach of debridement and BGIF can achieve the purpose of lesion removal, stability reconstruction in one stage, without the need for a supplementary posterior approach of internal fixation to strengthen cervical vertebral body stability.

In the treatment of patients with severe vertebral destruction, collapse, or vertebral dislocation, combined anterior and posterior approach surgery should be considered to reconstruct vertebral body stability when the anterior approach surgery alone cannot achieve stability reconstruction $[5,12,26,27]$. Combined anterior and posterior approach surgery (anterior approach of debridement or decompression combined with the posterior approach of pedicle screw fixation) is superior to only anterior approach surgery in biomechanical stability [28]. However, a change of surgical position was required by combined anterior and posterior approach surgery, more damage was also brought to this procedure, included man-made injury to surrounding tissues, longer operation time, and more blood loss. So the indications for this procedure need to be strictly controlled since its higher risks compared with anterior approach surgery alone. In this study, 5 patients were treated by combined anterior and posterior approach surgery, and the spinal cord compression symptoms were relieved. The preoperative local Cobb angle was improved from $26.18 \pm$ $9.93^{\circ}$ to $-11.05 \pm 5.02^{\circ}$ postoperatively. The SCA was improved from $98.76 \pm 4.61$ to $82.23 \pm 1.13$ postoperatively, and the C2C7SVA was improved from $32.44 \pm 4.24$ to $11.52 \pm 4.02$ postoperatively. The cervical vertebral sagittal sequence was corrected obviously, without postoperative broken screws, rods, or internal fixation loosening. As far as we considered, the combined anterior and posterior approach surgery should be selected in the following cases: a) severe vertebral bone destruction with vertebral instability; b) severe vertebral collapse, with pedicle bone destruction, with the severe imbalance of the cervical sagittal plane. c) Severe erosion of adjacent vertebral bodies with unilateral or pedicle destruction. In the surgical procedure, one-stage posterior approach surgery aimed to fix and decompress, remove the vertebral plate and decompress the capsule indirectly, to reduce the risk of anterior approach surgery. In the process of anterior approach debridement, more attention should be paid to the extent of resection, the decompression should be performed effectively for compression area, and resection of the posterior longitudinal ligament. The scope of the contralateral resection depends on the invasion of the lesion. In principle, the uncovertebral joint should not be removed, and complete lesion removal and vertebral body structural support are more critical. In our cohort, complications occurred in 1 of 5 patients who underwent combined anterior and posterior approach surgery. The muscle strength of both upper limbs decreased from grade 5 to grade 3 , with normal sensory function. After symptomatic treatment with neurotrophic drugs, the muscle strength returned to normal after 2 weeks.

The upper cervical spine is adjacent to important structures, such as the medulla oblongata and cerebellum, which makes the anatomy more complex. Especially in the treatment of vertebral artery variations and pedicle deformities, surgery is difficult and risky, because the intraoperative procedure leads to vertebral artery injury easily, and even respiratory failure and sudden death [27, 29]. The odontoid process and the $C 2$ vertebral body are involved by TB of the upper cervical spine. The odontoid process is an important structure, which connects the upper cervical joint. Severe bone destruction of the odontoid process can be caused by TB lesions, which makes the atlantoaxial intervertebral space separated, let the atlantoaxial dislocation and atlantoaxial instability occurred, then local blood flow in the odontoid process is poor. Imaging examination shows the mild erosion and destruction of the odontoid process at the early stage of disease, which will cause ischemic necrosis of the odontoid process in the advanced stage, and cause pathological fracture of the odontoid process. Afterward, the neck movement is limited, and the $\mathrm{C} 2$ vertebral body is severely collapsed, which will cause the cervical spine structure to unstable. Multilevel bone destruction also occurs in some patients with upper cervical TB, and several of them will be taken to cervical coronal imbalance and cervical deformity. The surgical treatment of upper cervical TB focuses on focal debridement, spinal cord decompression, and reconstruction of cervical stability. Given the choice of surgical methods, oral approach surgery has been utilized by some scholars to treat upper cervical TB $[30,31]$, and satisfactory postoperative results have also been received. This procedure can enter the lesion directly with the minor traumatic incision. However, postoperative cervical stability is poor in the treatment of patients with severe bone destruction, vertebral collapse, and atlantoaxial dislocation. It is also prone to breakage or displacement of the internal fixation device. The scope of surgery is deep and narrow, which leads to a high incidence of complications, such as oral mixed infection, retropharyngeal abscess, laryngeal edema, and cerebrospinal fluid leakage. The anterior approach of cervical postpharyngeal debridement combined with occipitocervical fusion for the treatment of upper cervical TB was applied by Wang et al. [5, 27], and 
good postoperative results were obtained. The advantages of this approach are the simple anatomical structure, which exposes the vertebral body through the esophageal sheath and the carotid sheath reduces the risk of peripheral nerve injury. However, the limited cervical movement was caused significantly, which decreased the quality of the patient's life. Besides, in combined anterior and posterior approach surgery, the main difference lied in the posterior approach of fixation method, fixation and fusion procedure of the atlanto-pivot, and occipitocervical fixation and fusion. Xing et al. [4] concluded that under the premise of removing the lesion, short-segment internal fixation and fusion should be used as far as possible to maximize the preservation of a cervical range of motion and minimize the loss of cervical range of motion, which is an important principle. In this study, there were 4 cases of upper cervical TB, 2 patients were treated by interbody fusion, and 2 patients were managed by atlanto-pivot fixation and fusion.

The simple anterior approach surgery was managed for patients with mild destruction of the odontoid process, no atlantoaxial dislocation, good stability of the upper cervical spine, or whose $\mathrm{C} 2$ without obvious vertebral collapse, $\mathrm{C} 2 / 3$ intervertebral space lesions, only slight infiltration of adjacent vertebral bodies, and no $\mathrm{C} 2$ pedicle destruction. For patients with severe atlas bone destruction with atlantoaxial joint and atlantooccipital joint instability, severe odontoid bone destruction with atlantoaxial dislocation, C2 vertebral bone destruction with severe vertebral collapse with unilateral and pedicle bone destruction, and C3 vertebral bone destruction with severe vertebral instability of vertebral collapse, the combined anterior and posterior approach surgery was applied. According to the extent of lesion involvement and the degree of vertebral destruction, an individualized surgical plan and standardized anti-TB chemotherapy were prepared, then satisfactory postoperative outcomes were obtained in the treatment of upper cervical TB using both surgical methods.

Our study of debridement and BGIF with different surgical approaches in the treatment of patients with kyphotic cervical TB provided some valuable clinic experience. Limitations of this study should also not be ignored. First of all, there is no mature treatment algorithm for the resolution of kyphotic cervical TB. In addition, there is a lack of large case series with the complete postoperative of infected kyphotic cervical TB treated with anterior or combined anterior and posterior approach surgery (debridement and BGIF). Hence, a prospective study of more samples and multi-center is of more clinical significance.

\section{Conclusions}

In this study, practical results were received by the application of anterior and combined anterior and posterior approach surgery in the treatment of kyphotic cervical TB. In all, for patients with kyphotic cervical TB, surgery of debridement and BGIF can achieve effectively neurological improvement, neck pain relief, kyphotic deformity correction, and reconstruction of spine vertebral body stability. The characteristics of the lesion, the degree and extension of kyphosis, and the degree of spinal cord and nerve compression damage can be presented clearly by the radiographic sagittal parameters. This does a favor to individualize the choice of surgical approach to achieve nerve decompression, debridement, fusion, and reconstruction of cervical stability, safely and effectively.

\section{Abbreviations}

A, anterior approach. AP, anterior approach combines with posterior approach. ASIA, American Spinal Injury Association spinal cord injury grade. BGIF, bone grafting using internal fixation. CRP, C-reactive protein. CT, computed tomography. ESR, erythrocyte sedimentation rate. JOA, Japanese Orthopedic Association cervical function score. MRI, magnetic resonance imaging. SVA, sagittal verticalaxis. SCA, spinocranial angle. NDI, neck disability index. NT, neck tilt. TIA, thoracic inlet angle. T1S, T1 slope. TB, tuberculosis. VAS, visual analog scale.

\section{Declarations}

\section{Ethics approval and consent to participate}

This retrospective study was approved by the Ethics Committee of The First Affiliated Hospital of Xinjiang Medical University and carried out in accordance with the ethical standards set out in the Helsinki Declaration. Written informed consent was received from all participating. 


\section{Consent for publication}

Written statements of consent to publish were received from the included participates.

\section{Availability of data and materials}

The data sets generated and analyzed during the current study are not publicly available due to restrictions on ethical approvals involving patient data and anonymity but can be obtained from the appropriate authors as reasonably required.

\section{Competing interests}

The authors declare that they have no conflict of interest.

\section{Funding}

This study was not funded by any foundation.

\section{Author Contributions}

HPL, KL, QD, and WBS developed the research questions and scope of the study. HPL and MM conducted preoperative and postoperative data screening, and data charting. HPL drafted the manuscript, prepare tables and figure with HLG's contribution. WBS developed the literature search strategies in collaboration with the other authors. HPL, KL, QD, WBS, MM, and HLG contributed to the organization, analysis, and interpretation of the results. All authors read and approved the final manuscript.

\section{Acknowledgments}

Not applicable.

\section{References}

1. Wang Y, Zhang H, Li M, Tang M, Guo C, Deng A, Gao Q, Wu J, Liu J: Debridement, interbody graft using titanium mesh cages, posterior instrumentation and fusion in the surgical treatment of multilevel noncontiguous spinal tuberculosis in elderly patients via a posterior-only. INJURY 2017, 48(2):378-383.

2. Li ZW, Li ZQ, Tang BM, Ren R, Zhang Y, Li CL, Zhang XB: Efficacy of One-Stage Posterior Debridement and Bone Grafting with Internal Fixation in the Treatment of Monosegmental Thoracolumbar Tuberculosis. WORLD NEUROSURG 2019, 121:e843e851.

3. Hsu LC, Leong JC: Tuberculosis of the lower cervical spine (C2 to C7). A report on $\mathbf{4 0}$ cases. J Bone Joint Surg Br 1984, 66(1):1-5.

4. Xing S, Gao Y, Gao K, Zhang G, Yu Z: Anterior Cervical Retropharyngeal Debridement Combined With Occipital Cervical Fusion to Upper Cervical Tuberculosis. SPINE 2016, 41(2):104-110.

5. Wang L, Liu L, Song Y, Pei F, Liu H: Cervical tuberculosis associated with cervical pain and neurologic deficit: a case report and literature review. SPINE J 2014, 14(5):e13-e18.

6. Bu G, Shuang F, Liu G, Wu Y, Hou S, Ren D, Shang W: Efficacy and Safety of One-Stage Selective Discectomy Combined with Expansive Hemilaminectomy in the Treatment of Cervical Spondylotic Myelopathy. WORLD NEUROSURG 2016, 94:507-512.

7. Zeng $H$, Shen $X$, Luo $C$, Xu Z, Zhang Y, Liu Z, Wang X, Cao Y: 360-degree cervical spinal arthrodesis for treatment of pediatric cervical spinal tuberculosis with kyphosis. BMC MUSCULOSKEL DIS 2016, 17(1). 
8. Yuan B, Zhao Y, Zhou S, Wang Z, Chen X, Jia L: Treatment for tuberculosis of the subaxial cervical spine: a systematic review. ARCH ORTHOP TRAUM SU 2020.

9. Walden JH, Schmitz J: Pott's Disease Resulting in Complete Cervical Vertebral Destruction. WILD ENVIRON MED 2018, 29(1):90-93.

10. Kotil K, Dalbayrak S, Alan S: Craniovertebral junction Pott's disease. BRIT J NEUROSURG 2009, 18(1):49-55.

11. Jain AK, Kumar J: Tuberculosis of spine: neurological deficit. EUR SPINE J 2013, 22 Suppl 4:624-633.

12. Rathod TN, Sathe AH, Marathe NA: It's Never Too Late: Neurological Outcome of Delayed Decompression in Tuberculosis of Spine. Global Spine J 2021, 11(5):716-721.

13. Mittal S, Jain AK, Chakraborti KL, Aggarwal AN, Upreti L, Bhayana H: Evaluation of Healed Status in Tuberculosis of Spine by Fluorodeoxyglucose-positron Emission Tomography/Computed Tomography and Contrast Magnetic Resonance Imaging. INDIAN J ORTHOP 2019, 53(1):160-168.

14. Jain AK, Sinha S: Evaluation of systems of grading of neurological deficit in tuberculosis of spine. SPINAL CORD 2005, 43(6):375-380.

15. Kalanjati VP, Oktariza RT, Yahya Y, Machin A: Paralytic ileus in the patient with tuberculosis of spine. Br J Neurosurg 2020, 34(6):602-603.

16. Sharma A, Chhabra HS, Chabra T, Mahajan R, Batra S, Sangondimath G: Demographics of tuberculosis of spine and factors affecting neurological improvement in patients suffering from tuberculosis of spine: a retrospective analysis of 312 cases. SPINAL CORD 2017, 55(1):59-63.

17. Churchyard GJ: A stratified approach to tuberculosis treatment. NAT MED 2018, 24(11):1639-1641.

18. ÖZDEMIR HM, US AK, ÖGÜN T: The role of anterior spinal instrumentation and allograft fibula for the treatment of Pott disease. Spine (Philadelphia, Pa. 1976) 2003, 28(5):474-479.

19. Zhu Z, Hao D, Wang B, Gao W, Yang R, Guo H, Wang Y, Kong L: Selection of surgical treatment approaches for cervicothoracic spinal tuberculosis: A 10-year case review. PLOS ONE 2018, 13(2):e192581.

20. Garg RK, Somvanshi DS: Spinal tuberculosis: A review. The Journal of Spinal Cord Medicine 2013, 34(5):440-454.

21. Arora S, Sabat D, Maini L, Sural S, Kumar V, Gautam VK, Gupta A, Dhal A: The Results of Nonoperative Treatment of Craniovertebral Junction Tuberculosis: A Review of Twenty-six Cases. The Journal of Bone and Joint Surgery-American Volume 2011, 93(6):540-547.

22. Furin J, Cox H, Pai M: Tuberculosis. The Lancet 2019, 393(10181):1642-1656.

23. Pigrau-Serrallach C, Rodríguez-Pardo D: Bone and joint tuberculosis. EUR SPINE J 2013, 22(S4):556-566.

24. Yang S, Wang D, Xu J, Luo F, Wu W, Zhang Z: A multicenter retrospective research of anterior debridement, decompression, bone grafting, and instrumentation for cervical tuberculosis. NEUROL RES 2019, 41(12):1051-1058.

25. Zhang Y, Deng L, Zhang X, Yu X, Ai Z, Mei Y, He F, Yu H, Zhang L, Xiao X et al: Three-Dimensional Printing-Assisted Cervical Anterior Bilateral Pedicle Screw Fixation of Artificial Vertebral Body for Cervical Tuberculosis. WORLD NEUROSURG 2019, 127:25-30.

26. Wu W, Li Z, Lin R, Zhang H, Lin J: Anterior debridement, decompression, fusion and instrumentation for lower cervical spine tuberculosis. J ORTHOP SCI 2020, 25(3):400-404.

27. Wang B, Shang R, Yang T, Zhang H, Hu H, Hu W, Hao D: Evaluation of clinical outcomes of one-stage anterior and posterior surgical treatment for atlantoaxial tuberculosis complicated with neurological damage. BMC MUSCULOSKEL DIS 2019, 20(1).

28. Richman JD, Daniel TE, Anderson DD, Miller PL, Douglas RA: Biomechanical evaluation of cervical spine stabilization methods using a porcine model. Spine (Phila Pa 1976) 1995, 20(20):2192-2197.

29. Arora S, Sabat D, Maini L, Sural S, Kumar V, Gautam VK, Gupta A, Dhal A: The results of nonoperative treatment of craniovertebral junction tuberculosis: a review of twenty-six cases. J BONE JOINT SURG AM 2011, 93(6):540-547.

30. Frempong-Boadu AK, Faunce WA, Fessler RG: Endoscopically assisted transoral-transpharyngeal approach to the craniovertebral junction. NEUROSURGERY 2002, 51(5 Suppl):S60-S66.

31. Kotil K, Dalbayrak S, Alan S: Craniovertebral junction Pott's disease. Br J Neurosurg 2004, 18(1):49-55. 


\section{Figures}

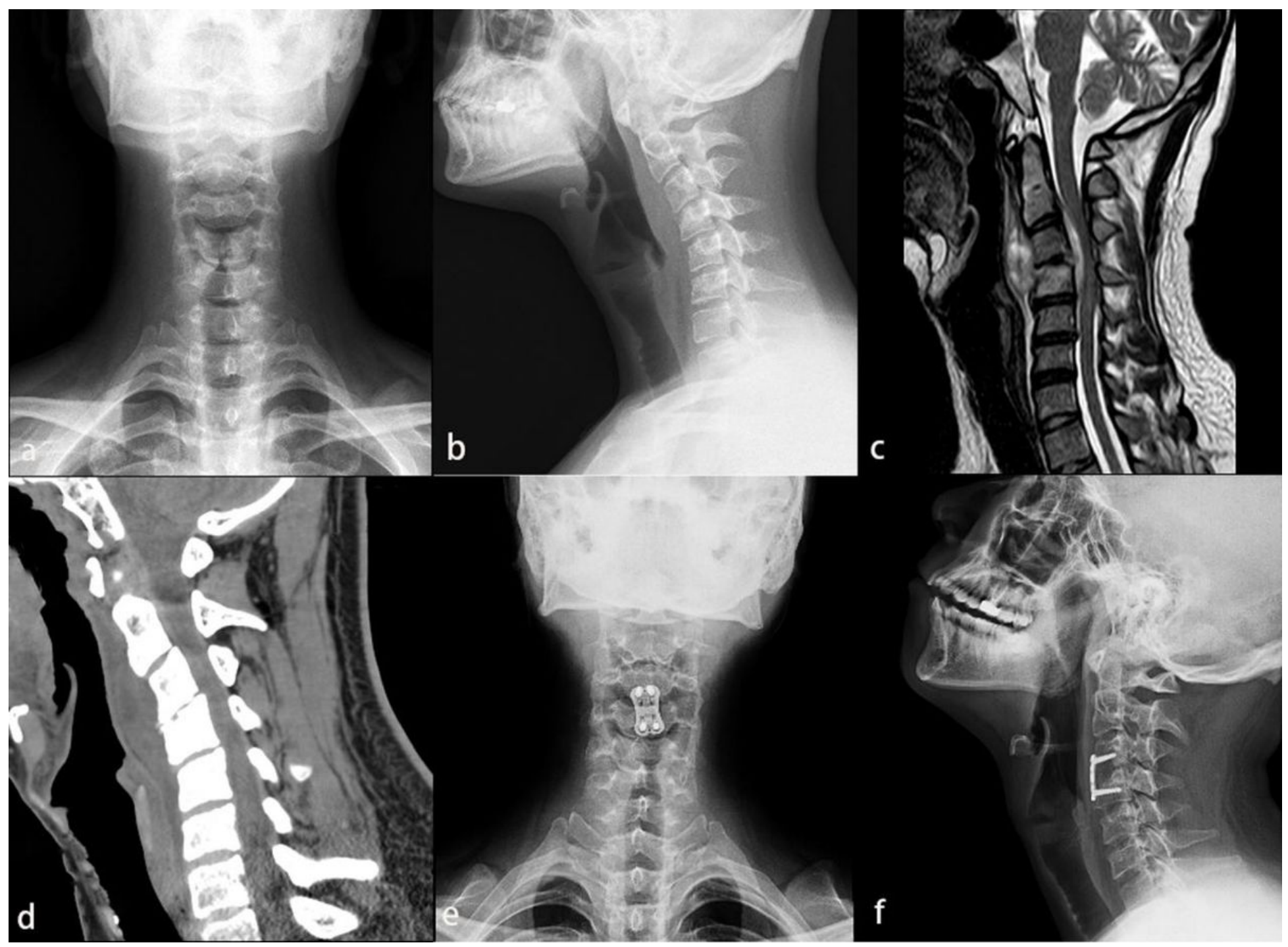

\section{Figure 1}

A 27-year-old woman with limited neck pain and mobility for 7 months and progressive limb weakness for 2 weeks. a, b) cervical anteroposterior and lateral X-ray showed C3, C4 vertebral destruction, C2 C4 local kyphosis. c) cervical MRI showed C3, C4 vertebral body partial loss, local kyphosis, and there was a significant abscess in front of the vertebral body. d) cervical CT showed C3 and C4 vertebral destruction. e, f) postoperative anteroposterior and lateral X-ray showed C3 and partial C4 vertebrectomy, cervical sequence was corrected, and partial bone grafting fusion with stable internal fixation position. 


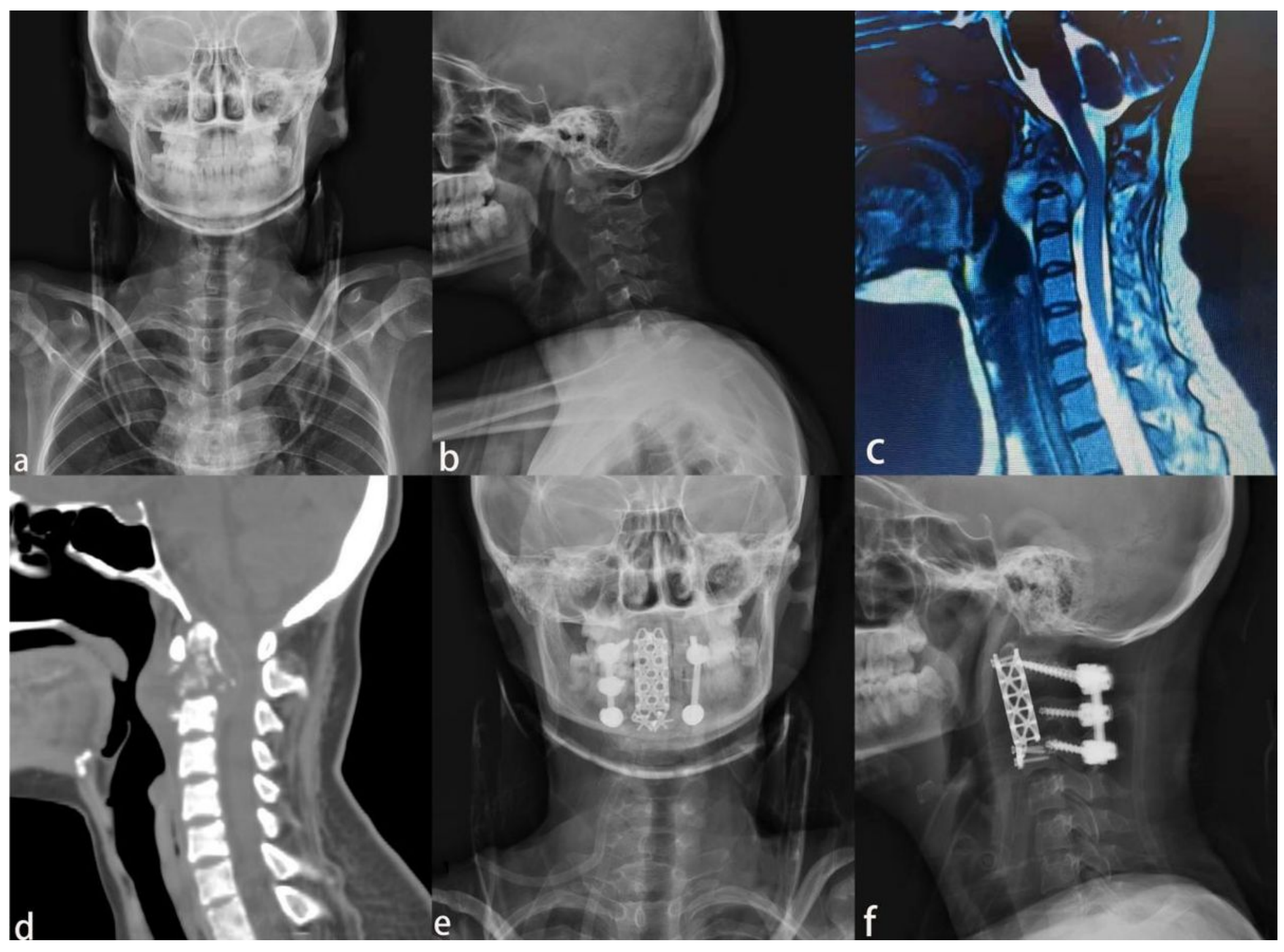

Figure 2

A 23-year-old woman with a 3-month history of limited neck pain and mobility and 1-week history of progressive weakness of the extremities. a, b) anteroposterior and lateral X-ray showed C1 and C2 vertebral destruction and local kyphosis from C1 to C3. c) cervical MRI showed significant loss of $\mathrm{C} 2$ vertebral body height, local kyphosis, compression of the sac, and localized prevertebral abscess. d) cervical CT showed C1 and C2 vertebral destruction, intraspinal encroachment, and local kyphosis from C1 to C3. e, f) postoperative anteroposterior and lateral X-ray showed C2 and partial C3 vertebrectomy, vertebral body reconstruction using titanium cage, and posterior approach surgery using cervical 2 pedicle screw and cervical 3, 4 lateral mass screw fixation. 